\title{
Delivery of pain education through picture-telephone videoconferencing for veterans with chronic, non-cancer pain
}

\author{
David Cosio* and Erica HL \\ Jesse Brown VA Medical Center, Anesthesiology/Pain Clinic, Chicago, USA
}

\begin{abstract}
Almost a quarter of Veterans nationwide live in rural communities, which may negatively impact their health-related quality of life compared to their counterparts in urban areas. The high rates of chronic pain amongst rural Veterans coupled with the barriers found in these areas complicate the delivery of pain self-management interventions. Technology-assisted treatments, or telehealth, may provide a comparable alternative to face-to-face interventions. The "Pain Education School" program has been shown to positively impact Veterans stage of change, their experience of pain, and their mood. The purpose of the current feature is to propose the feasibility and potential efficacy of using picture-telephone (PICTEL) videoconferencing technology to disseminate a pain education program to rural Veterans with chronic, non-cancer pain. The current study used a retrospective outcome design with a sample of 463 Veterans aged 18-88 years old with mixed idiopathic, chronic, non-cancer pain conditions who participated in the Pain Education School program either face-to-face or via PICTEL at a Midwestern VA Medical Center between January 8, 2010-November 4, 2011. The preliminary findings of the current study suggest that the use of PICTEL technology to disseminate pain education to remote clinics may be comparable to face-to-face interventions. A positive preliminary study is promising and such a telehealth program is feasible within the VA system.
\end{abstract}

\section{Introduction}

Approximately $23 \%$ of the 22 million Veterans nationwide live in rural communities, which is disproportionate when you consider that only $18 \%$ of the US population resides in these areas [1]. In addition, about $44 \%$ of active duty service members come from rural regions [2] about $57 \%$ of these rural Veterans are enrolled in the U.S. Department of Veterans Affairs (VA) health care system [3]. Pain is one of the most common reasons Veterans consult with their primary care providers and is one of the most prevalent symptoms reported by returning Veterans.4 In fact, about half of the Veterans within VA health care settings experience pain regularly.5 Additionally, Veterans in rural communities have been found to have lower health-related quality of life compared to their counterparts in urban areas [2]. The incidence of chronic pain is higher in rural areas because the population is often older, obese, and impoverished. Social factors also play a role, such as limited access of pain specialists, transportation issues, unstable housing, poor education, and unemployment. The high rates of pain amongst Veterans coupled with the barriers found in rural areas increase the likelihood of primary care providers assessing and treating chronic pain rather than pain specialists. Thus, clinical care at a distance is progressing as a model and is being used more frequently to treat disease in rural areas. Dial-up phones and videocassette recording devices are both examples of technologies that have become obsolete, but new, amazing devices and applications are coming on the market every day (e.g. at-home patient monitoring and wearable technology) that allow services to be provided at a distance.

Past research has shown that using technology to deliver pain selfmanagement interventions produced positive results [6-8]. However, it is still unclear if interventions provided using technologies are as effective as their face-to-face counterparts. There is also not enough evidence to suggest the superiority of one modality over another. In addition, there seems to be little guidance on intervention development. However, treatment retention and outcomes have been shown to improve [9]. There are several benefits and challenges to implementing technology-assisted interventions. Even though the use of technology can improve access to treatment, circumvent some of the barriers faced by patients, and provide an avenue for maintenance of gains; technology-assisted interventions may introduce other difficulties, such as the need to supplement it with understandable materials, promote engagement and retention of patients, encourage the practice and use of skills learned, and take steps to ensure patient safety.

In 2014, the VA announced that 690,000 Veterans had received care via telehealth that year, which was about $12 \%$ of all Veterans enrolled in the system [10]. The term "telehealth" applies to the use of technologies to provide clinical care and patient education in circumstances where distance separates those services and those providing services in real time. However, there continues to be a need for greater outreach using electronic information and communication technology to ensure excellence in health care delivered to our nations Veterans. According to the Institute of Medicine, people with chronic pain have substantial unmet educational needs [11]. Moreover, patients tend to disregard or ignore information about the reliability and validity of health materials to which they are exposed [12].

Correspondence to: David Cosio, 820 S Damen Ave \#124Chicago, IL 60612, USA, Tel: (312)569-8703; Fax: (312)569-8120; E-mail: david.cosio2@va.gov

Received: June 15, 2016; Accepted: June 20, 2016; Published: June 25, 2016 


\section{Background information}

The face-to-face "Pain Education School" was developed at a Midwestern VA Medical Center in November 6, 2009 to address the health education needs of Veterans who suffer from chronic, noncancer pain in the catchment area. Research findings from the first year of the in-person "Pain Education School" program [13] suggested that Veterans who participated in the program moved from a contemplative to a preparation stage of change, witnessed improvement in the experience of their pain, and exhibited an improvement in their mood [14]. During the development and implementation of the pain education program, it was also determined that there would be many Veterans who would be unable to access this program due to environmental barriers (i.e., transportation) if the program was only made available at the main hospital (VA). Approximately $22 \%$ of Veterans in the current VA system are served by community-based outpatient clinics (CBOCs), which could serve as another avenue of providing care if telehealth technologies were used.

Past research has provided a range of evidence indicating that interventions for a variety of chronic conditions delivered by videoconferencing produced similar outcomes to treatment delivered in-person. 15,16 In addition, research has found that videoconferencing is feasible as a means of delivering therapeutic interventions for people with chronic conditions in rural communities [16,17]. However, research support for group, pain education programs addressing chronic, non-cancer pain utilizing clinic-based videoconferencing is lacking. Thus, the current investigators applied picture-telephone (PICTEL) videoconferencing technology in January 8, 2010 to the program in order to outreach to rural Veterans in CBOC A (population 27,880 and 46 miles away) and then in November 5, 2010 to CBOC B (population 30,293 and 37 miles away). The term "rural" is hereafter defined as nonmetropolitan areas of the US that are communities of 50,000 residents or less and more than 20 miles from the Midwestern VA Medical Center. According to the Veterans Access, Choice, and Accountability Act of 2014 [18] environmental barriers and their "burden" may be defined as the Veteran residing 20 miles from a full-service VA medical facility. The purpose of the current feature is to propose the feasibility and potential efficacy of using PICTEL technology to disseminate a pain education program to rural Veterans with chronic, non-cancer pain. The level of specificity provided below may be helpful to other VA facilities trying to implement a similar program.

\section{Methods}

\section{Clinical protocol}

Veterans were referred to the "Pain Education School" program by their primary care provider. The investigators would receive the consult through the computerized patient record system (CPRS) and determine the closest location to the Veteran (VA, CBOC A, or CBOC $B)$. The Veteran was then sent a letter two weeks before the scheduled appointment about the location, time, and place of their appointment. The participant then attends their first one-hour class session after the introduction class. The participant is scheduled and encouraged to attend 11 subsequent weeks of one-hour classes led by guest speakers from 23 different disciplines within the VA. The program provides a menu of treatment modalities-the presenters rotated on a schedule, not the Veterans. Presenters from each discipline shared information about chronic, non-cancer pain from their perspective, available treatments within their service, and how to access their respective clinics.

\section{Logistics and considerations}

The program is coordinated by two assigned pain providers who are charged with the tasks of scheduling and contacting patients and presenters; maintaining communication and troubleshooting with the telehealth clinical technician; setting up and coordinating all the sites (VA, CBOC A, and CBOC B); checking patients in at the time of the appointment; completing patient encounters at the distant site (VA); promoting the services to potential referral providers; and transferring materials across sites.

The role of the assigned telehealth clinical technician is outlined in a telehealth service agreement, which defines the responsibilities and procedures involved in establishing and operating a telehealth clinic between the involved medical facilities. Telehealth care providers are credentialed and privileged to provide the above noted clinical service(s) at both the originating (CBOC) and the distant (VA) facilities. Therefore, there is always two technicians present during each program, one at either side.

\section{Technology troubleshooting}

The telehealth department provides technical support for providers to ensure clinical efficiency and effectiveness during a telehealth visit. Specifically, the facility telehealth coordinator ensures that there is adequate technology infrastructure, bandwidth, and technical support to ensure there is an efficient group encounter. Biomedical engineering assists in the setup of pertinent equipment used for telehealth videoconferencing. The telehealth clinical technician takes the initial steps in troubleshooting. If after the initial troubleshooting it is deemed that the equipment requires further action to resolve the problem, the telehealth clinical technician contacts the national telehealth technology help desk for support [19].

\section{Workload capture}

As with any medical visit, intervention, or encounter the clinical documentation of the event is very important. Telehealth visits are documented in CPRS and the notes include all pertinent information. The rendering provider closes out the appointment at the distant site (VA) and also provides the same information to the originating site (CBOC). The information required for the patient care encounter to close the appointment must be provided to the telehealth clinical technician by the provider. The telehealth clinical technician at the CBOC validates workload encounters using the Healthcare Common Procedure Coding System code Q3014, “telehealth originating site facility fee [20]. Workload will be obtained using encounter data and clinic designation. The creation of encounter forms, progress notes, and the consult templates to telehealth visits are also essential. To ensure the facility receives accurate workload and to evaluate the economic and other impacts of the telemedicine programs, sources such as the data warehouse and the virtual care modality report are used to verify accurate workload credit [19].

\section{Pictel technology}

The current Midwestern VA Medical Center system uses 42-inch plasma televisions connected to Tandberg Codec C40's. The Tandberg Codec $\mathrm{C} 40$ provides all the power required to transform any conference room to a $1080 \mathrm{HD}$ video multimedia presentation [21]. The codec is a device, either hardware or software based, that encodes analog video/ audio signals to digital video/audio, and vice versa. For the purposes of the "Pain Education School," multipoint videoconferencing with a multipoint control unit allows for three or more locations to 
participate in a telehealth modality. During a multipoint encounter, there are two modes available to support the session. In a continuous presence videoconference, all participants can be seen at the same time on the monitor with microphones off mute. In the voice activated mode, microphones at all the sites can be active all at once, but should be placed on mute except for the presenter or if a participant has a question. This prevents extraneous noises and interruptions. Use of PowerPoint or other information can be displayed as needed.

\section{Best practices and etiquette}

There are several best practices for conducting a successful videoconference which occur either before or during the meeting [22]. Before each meeting, the coordinators and telehealth clinical technicians are tasked with checking the room to ensure the seating arrangement will allow everyone to be properly viewed, making sure all media (PowerPoints, audio, and video clips) are fully functioning, and troubleshooting the equipment at least 30-45 minutes ahead of the scheduled meeting. To avoid having technical difficulties and to ensure success of the telehealth program, it is important to build close relationships with the support staff, such as room schedulers, public affairs officers, environmental management services, biomedical electronic services, and escort services. The authors have learned over time that these are often times relationships that may be overlooked and are actually necessary for a telehealth education program to be realized (Figure 1).

Conducting a successful videoconference also requires a certain level of etiquette. For example, the microphone should remain muted until the videoconference starts or until the distant facility wishes to speak to the originating sites. During the meeting, the coordinators introduce the presenters for the day; ensure the presenters are facing the camera; and allow approximately 5-10 minutes before the class wrap-up to answer any questions, review important items, and confirm the next class date and time. The presenter, on the other hand, needs to make sure they look into the camera when speaking; speak in a normal tone; avoid noisy activities (e.g., tapping a pen or whispered side conversations); and slow their speaking pace slightly to accommodate split-second delays when transmitting over long distances. The role of the participant is to engage in the learning process and raise their hand to be recognized by the facilitator if they want to speak.

\section{Quality management}

To measure the efficacy of using PICTEL for pain education, an Institutional Review Board proposal and the Research and

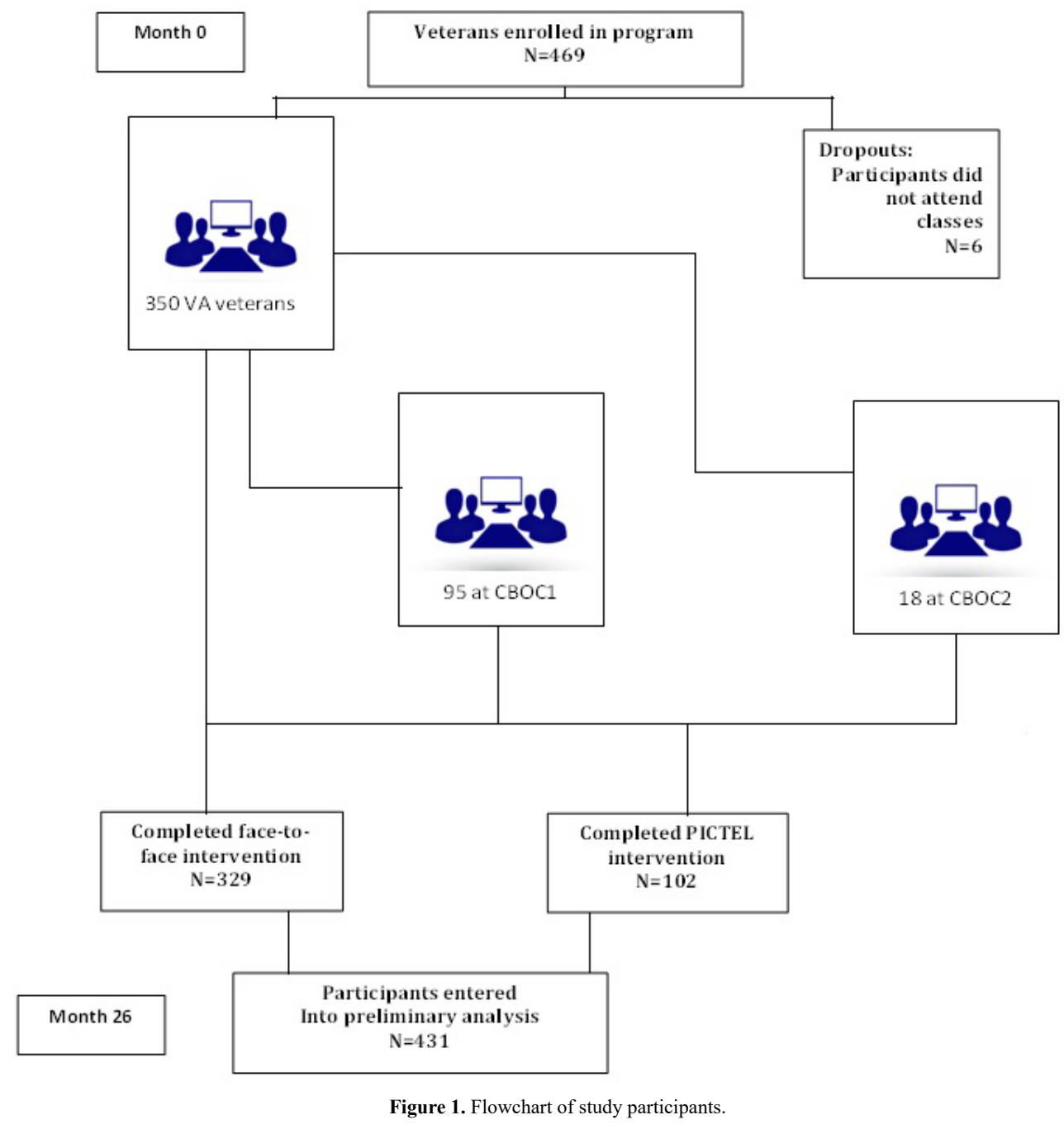


Development Office Request were submitted to the participating VA. The current study used a retrospective outcome design with a sample of 463 Veterans aged 18-88 years old with mixed idiopathic, chronic, non-cancer pain conditions who participated in the Pain Education School program either face-to-face $(\mathrm{N}=350 ; 76 \%)$ or via PICTEL $(\mathrm{N}=113 ; 24 \%)$ at a Midwestern VA Medical Center between January 8,2010 -November 4,2011 . There were no exclusion criteria used for the study. As a part of quality management, measures were completed by participants of the face-to-face and PICTEL interventions at the introduction and conclusion of the program. The assessments included a battery of measures, including the Readiness Questionnaire (M. Jensen, personal communication, August 23, 2004), the Patient Pain Questionnaire (PPQ) [23] and the Patient Health Questionnaire (PHQ-2) [24]. The single item Readiness Questionnaire measures the patient's stage of readiness to adopt a self-management approach to their pain. The temporal stability of the Readiness Questionnaire $(r=$ 0.63) has been found to be reliable [14]. The PPQ measures the level of knowledge and experience of the patient in managing their pain. The PPQ has historically been tested with established reliability and validity [23] The PHQ-2 measure inquires about the frequency of feeling down, depressed, and hopeless and anhedonia over the past two weeks. A PHQ-2 score $\geq 3$ has a sensitivity of $83 \%$ and a specificity of $92 \%$ for major depression [24]. At the end of the program, Veterans completed a feedback form which addressed patient satisfaction with the program. A recent study found that Veterans who participated in the pain education program reported learning "new and useful" information, perceived the program as "easy to understand," used the learned information, and recommended the program to others [25]. In addition, $4 \%$ of the program's participants specifically commented on the statement, "If I could change anything...," in reference to the CBOC or the PICTEL technology. In particular, comments were made about "having a better setup" at the CBOC and making "more information from the program (available on the technology)." Veterans voluntarily participated in the "Pain Education School" program and were free to withdraw at any time.

\section{Results}

Preliminary findings from the current study propose there was no significant difference between the face-to-face and PICTEL interventions on any of the outcome measures aforementioned. However, the preliminary findings from the current study support past research which has found a significant difference between the pre- and post-measures of the participants' stage of readiness to adopt a selfmanagement approach, their experience of pain, and the frequency of their depressed mood, regardless of how the intervention was delivered [14]. These results suggest the "Pain Education School" telehealth program had a moderate effect in increasing participants' readiness to adopt a self-management approach. In addition, the current findings suggest the telehealth program had a small to moderate effect in decreasing the negative experience of pain. Finally, the results suggest the telehealth program had a small to moderate effect in decreasing depressive symptoms. The preliminary findings mirrored those of previous non-cancer pain research in which Veterans participating in a pain education program did not evidence increased pain knowledge [14]. A prior research study found that the addition of audience response systems to the pain education program at a VA demonstrated significantly greater increases in pain knowledge compared to those locations ( $\mathrm{CBOC} 1$ and $\mathrm{CBOC} 2$ ) without the technology by facilitating active learning [26].

\section{Discussion}

The "Pain Education School" is a unique program developed and implemented in the VA system using PICTEL technology to provide education to the rural Veteran population. The program delineated in this feature may prove to be an avenue by which rural Veterans can bypass identified barriers and realize self-management goals by empowering them to self-tailor their own pain management plans. The preliminary findings of the current study suggest that the use of PICTEL technology to disseminate pain education to remote VA CBOC's may be comparable to face-to-face interventions. The current study also underlines the importance of making partnerships, having support from administration, marketing, and obtaining knowledge about the healthcare system in order to have a successful telehealth program. Despite the current intervention having positive findings, there continues to be a need to address some problematic areas. An important lesson learned during the implementation process was how to handle frequent technical issues with the equipment. This could be potentially resolved by having a telehealth clinical technician and/or personnel from biomedical electronic services present during the entire program time to ensure proper set-up and function of the equipment. Another lesson learned was the need for the telehealth clinical technicians assigned to take on additional responsibilities beyond those outlined on the telehealth service agreement at the $\mathrm{CBOC}$ sites. Thus, the description of their responsibilities would have to be amended to include these additional duties in light of the findings from past research. It also proved difficult to make materials available to the Veterans at the CBOC's as mentioned in the previous satisfaction survey study and there was a higher attrition rate witnessed in the current preliminary study due to incomplete measures. Finally, there is a need to increase program exposure to Veterans directly in the CBOC clinics. Most of the referrals come from the VA providers themselves, which does not account for a provider effect nor consider whether Veterans would have self-referred and engaged in the program with improved marketing. This could be potentially resolved by setting up program boards at the CBOC's in order to post class offerings at those locations.

\section{Conclusion}

Despite any limitations, technology-administered interventions constitute a potentially cost-effective way to reach large numbers of rural Veterans who cannot access services needed to facilitate their pain management efforts. There are merits to the current videoconferencing format, but a lot of the recent studies on mobile health and internetbased training programs address transportation and time-related barriers. Despite these advancements, there continues to be issues related to trust, quality, security, privacy, and reimbursement with these newer formats. Therefore, videoconferencing may serve as the best option for telehealth care in the current healthcare system. Before videoconferencing programming can be widely disseminated, more large-scale, multisite, and scientifically-rigorous evaluations of this program are needed. This feature serves as encouragement for other VA's to transfer this low-intensity approach as a means of creating awareness, and may be utilized as a benchmark for distance-learning within the healthcare system.

\section{Acknowledgements}

The authors have no conflicts of interest to disclose at this time. The authors would like to thank all the Veterans and providers who contributed to the Pain Education School program. The authors 
also thank all the technicians who contributed to the successful implementation of the telehealth program, including Cyndi Berg, RN; Laura Pistello; Kristen Wood; Janet Dumas-Chavis; and Martin Munoz, the facility telehealth coordinator. Most of all, the authors would like to thank the Jesse Brown VA Medical Center and the Anesthesiology/ Pain Clinic department for their vision and ongoing support of the Pain Education School program.

\section{References}

1. Office of Rural Health (2015) Annual Report: Thrive. Available at: http://www. ruralhealth.va.gov/docs/ORH_Annual_Report_2015_FINAL.pdf.

2. Weeks WB, Wallace AE, Wang S, Lee A, Kazis LE (2006) Rural-urban disparities in health-related quality of life within disease categories of Veterans. J Rural Health 22: 204-211. [Crossref]

3. Gironda RJ, Clark ME, Massengale JP, Walker RL (2006) Pain among veterans of Operations Enduring Freedom and Iraqi Freedom. Pain Med 7: 339-343. [Crossref]

4. Kerns RD, Otis J, Rosenberg R, Reid MC (2003) Veterans' reports of pain and associations with ratings of health, health-risk behaviors, affective distress, and use of the healthcare system. J Rehabil Res Dev 40: 371-379. [Crossref]

5. Bender JL, Radhakrishnan A, Diorio C, Englesakis M, Jadad AR (2011) Can pain be managed through the Internet? A systematic review of randomized controlled trials. Pain 152: 1740-1750. [Crossref]

6. Heapy AH, Higgins D, Cervone D, Wandner L, Fenton BT (2015) A systematic review of technology-assisted self-management interventions for chronic pain: Looking across treatment modalities. Clin J Pain 31: 470-492.

7. Lieberman G, Naylor MR (2012) Interactive voice response technology for symptom monitoring and as an adjunct to the treatment of chronic pain. Transl Behav Med 2: 93-101. [Crossref]

8. Newman MG, Szkodny LE, Llera SJ, Przeworski A (2011) A review of technologyassisted self-help and minimal contact therapies for anxiety and depression: Is human contact necessary for therapeutic efficacy? Clin Psychol Rev 31: 89-103.

9. Comstock J (2015) Telehealth served 12 percent of VA-covered Veterans in 2014. MobiHealthNews.com. Available at: http://mobihealthnews.com/37325/telehealthserved-12-percent-of-va-covered-veterans-in-2014/

10. Institute of Medicine (2011) Relieving Pain in America: A Blueprint for Transforming Prevention, Care, Education, and Research. Washington, DC: National Academic Press.

11. Gaglio B, Glasgow RE, Bull SS (2012) Do patient preferences for health information vary by health literacy or numeracy? A qualitative assessment. J Health Commun 17 Suppl 3: 109-121. [Crossref]

12. Cosio D, Hugo E, Roberts S, Schaefer D (2012) A Pain education school for Veterans with chronic non-cancer pain: Putting prevention into VA practice. Fed Pract 29: 23-29.

13. Cosio D, Lin EH (2013) Effects of a pain education program for veterans with chronic noncancer pain: a pilot study. J Pain Palliat Care Pharmacother 27: 340-349. [Crossref]

14. Kairyab D, Lehouxac P, Vincentde C, Visintinb M (2009) A Systematic review of clinical outcomes, clinical process, healthcare utilization and costs associated with telerehabilitation. Disabil Rehabil 31: 427-447.

15. Steel K, Cox D, Garry H (2011) Therapeutic videoconferencing interventions for the treatment of long-term conditions. J Telemed Telecare 17: 109-117. [Crossref]

16. Jennett PA, Affleck Hall L, Hailey D, Ohinmaa A, Anderson C, et al. (2003) The socioeconomic impact of telehealth: a systematic review. J Telemed Telecare 9: 311-320. [Crossref]

17. House Committee on Veteran's Affairs. Veterans Access, Choice, and Accountability Act of 2014. Available at: https://veterans. house.gov/the-veterans-access-choice-andaccountability-act-of-2014-highlights

18. Department of Veteran Affairs (2015) VISN-12 Operations Manual for Clinic-based Telehealth.

19. Centers for Medicare \& Medicaid Services. Healthcare Common Procedure Coding System Quarterly Update. Available at: https://www.cms.gov/Medicare/Coding/ HCPCSReleaseCodeSets/HCPCS-Quarterly-Update.html

20. Tandberg (2015) The Physical Interface Guide: Tandberg Codec C40. Available at http:// www.cisco.com/c/dam/en/us/td/docs/telepresence/endpoint/codec-c-series/ physical_interface_guide/tandberg_codec-c40_physical_interface_guide_tc30.pdf.

21. Advanced Etiquette (2015) 8 Tips for Video Conferencing Etiquette. Available at http://www. advancedetiquette.com/2013/04/8-tips-for-video-conferencing-etiquette/.

22. Ferrell BR, Rhiner M, Ferrell BA (1993) Development and implementation of a pain education program. Cancer 72: 3426-3432. [Crossref]

23. Kroenke K, Spitzer RL, Williams JB (2003) The Patient Health Questionnaire-2 validity of a two-item depression screener. Med Care 41: 1284-1292. [Crossref]

24. Watson EC, Cosio D, Lin EH (2014) Mixed-method approach to veteran satisfaction with pain education. J Rehabil Res Dev 51: 503-514. [Crossref]

25. Simmons EB, Cosio D, Lin EH (2015) Using audience response systems to enhance chronic, non-cancer pain knowledge acquisition among Veterans. Telemed $J$ E Health 21: 557-563.

Copyright: (C2016 Cosio D. This is an open-access article distributed under the terms of the Creative Commons Attribution License, which permits unrestricted use, distribution, and reproduction in any medium, provided the original author and source are credited. 